\title{
Studi Kehilangan Air PDAM Tirta Bukae Luwu Utara (Studi Kasus Kec. Masamba) Tahun 2017 - 2018
}

Andi Kartini Sari

Fakultas Teknik, Jurusan Sipil, Universitas Andi Djemma Palopo

email: tin_sary@yahoo.com

\begin{abstract}
ABSTRAK
Kehilangan air merupakan permasalahan besar yang mendapat perhatian serius dari setiap Perusahaan Daerah Air Minum (PDAM) karena tingkat kehilangan air merupakan salah satu indicator ketidakberhasilan perusahaan. Hal ini juga mendapat perhatian dari pemerintah yang diwujudkan dengan dikeluarkannya standar kehilangan air sebesar 20\% bagi setiap Perusahaan Daerah Air Minum (PDAM). Tingkat kehilangan air Perusahaan Daerah Air Minum (PDAM) di seluruh Indonesia rata-rata masih berada jauh di atas $20 \%$ dan disadari bahwa komponen yang cukup besar memberikan konstribusi terhadap kehilangan air adalah kebocoran., Sehingga perlunya diketahui seberapa besar tingkat kehilangan air dan kerugian PDAM akibat kehilangan air pada sistem distribusi air bersih PDAM Tirta Bukae wilayah Kec. Masamba antara tahun 2017-2018 dan faktor apa saja yang dapat mempengaruhi meningkatnya tingkat kehilangan air PDAM tersebut, sehingga mampu memecahkan permasalahan diwilayah tersebut.

Jumlah pelanggan yang terlayani oleh PDAM Tirta Bukae Luwu Utara Kec.Masamba tahun 2017 sebanyak 2.407 pelanggan dan tahun 2018 mengalami peningkatan dengan jumlah pelanggan sebanyak 2.660 pelanggan dengan jumlah volume produksi PDAM Tirta Bukae Luwu Utara Kec.Masamba tahun 2017 sebesar $1.306 .305 \mathrm{~m}^{3}$ dan tahun 2018 sebesar $1.470 .533 \mathrm{~m}^{3}$, Volume distribusi PDAM Tirta Bukae Luwu Utara Kec.Masamba tahun 2017 sebesar $1.280 .810 \mathrm{~m}^{3}$ dan tahun 2018 sebesar $1.456 .430 \mathrm{~m}^{3}$, Sehingga besar kehilangan air PDAM Tirta Bukae Luwu Utara Kec.Masamba pada tahun 2017 mencapai $430.684 \mathrm{~m}^{3}$ dengan kerugian mencapai Rp. 1.110.734.036 dan pada tahun 2018 mencapai 488.235 dengan total kerugian mencapai Rp. 1.259.158.065. Strategi pengendalian tingkat kehilangan air yang disarankan untuk dilakukan adalah penggantian meter air yang tepat dan sesuai dengan kelompok pelanggan yang menggunakan, dilakukan kalibrasi pada meter air pelanggan secara berkala, penerapan sistem pembacaan meter air pelanggan menggunakan alat komunikasi (HP) secara menyeluruh, membentuk tim penertiban sambungan liar, memantau pelayanan air yang tidak teratur, pemasangan water meter pada jaringan transmisi dan distribusi, membuat pemetaan jaringan menggunakan GIS, membentuk tim pengendalian NRW, dan pencarian kebocoran.
\end{abstract}

Kata Kunci : Kehilangan air, PDAM, Kebocoran

\section{PENDAHULUAN}

Kehilangan air merupakan salah satu masalah yang sering dialami oleh PDAM di Indonesia. Menurut data resmi PDAM Tirta Bukae Luwu Utara untuk Kecamatan Masamba tahun 2018 rata-rata kehilangan air PDAM Tirta Bukae Luwu Utara untuk Kecamatan Masamba mencapai sekitar $33.39 \%$ yaitu sebesar $486.235 \mathrm{~m}^{3}$. Tingkat kehilangan air yang tinggi sangat mempengaruhi kemampuan suplai air bersih PDAM terhadap konsumen. Semakin besar tingkat kehilangan air yang terjadi maka kemampuan suplai air bersih PDAM semakin menurun, karena PDAM akan terus merugi dari tahun ke tahun.

Kehilangan air terdiri dari kehilangan yang disebabkan oleh fisik (teknis) dan kehilangan yang disebabkan oleh non fisik (komersial).
Penyebab utama kehilangan air oleh fisik disebabkan oleh kebocoran pipa dan limpahan tangki reservoir. Sedangkan kehilangan air non fisik disebabkan beberapa faktor diantaranya konsumsi tak resmi, ketidakakuratan meter pelanggan, dan kesalahan penanganan data. Tindakan yang diperlukan untuk mengurangi tingkat kehilangan air ialah mengidentifikasi seberapa besar dan dimana kehilangan air terjadi serta kerugian finansial akibat kehilangan air tersebut. Besarnya nilai finansial kerugian akibat kehilangan air komersial merupakan alasan yang kuat mengapa harus dilakukan berbagai upaya untuk menurunkan tingkat kehilangan air komersial pada PDAM. Analisis terhadap unsur-unsur penyebab kehilangan air komersial perlu dilakukan guna melakukan pendekatan langkah-langkah pengendalian 
kehilangan air yang sesuai. Pengendalian kehilangan air yang sesuai dengan masalah yang dihadapi sangat diperlukan guna mencapai hasil yang maksimal.

\section{TINJAUAN PUSTAKA}

\section{A. Kebocoran Air}

Kebocoran air pada pelanggan PDAM dapat kita temui diberbagai tempat. Sebagian besar kebocoran tersebut adalah kebocoran kecil yang tidak terlihat oleh kasat mata manusia. Keadaan tersebut seringkali tidak diketahui oleh pelanggan PDAM, dan terkesan diremehkan. Tentunya hal tersebut tidak disengaja oleh pelanggan, dan akan berdampak pada pemborosan air dan membengkaknya biaya tagihan rekening air bagi si pelanggan, serta merugikan bagi pelanggan. Oleh sebab itu, untuk memudahkan dalam mendeteksi kebocoran air pada pelanggan, khusunya kebocoran-kebocoran yang tidak terlihat oleh kasat mata, maka dirancang sebuah alat untuk mendeteksi kebocoran menggunakan sensor waterflow yang di lihat dari besar debit air yang mengalir pada rotor sensor

\section{B. Aspek Teknis}

\section{Sistem Distribusi Air}

Air yang telah diproduksi di unit produksi harus didistribusikan kepada masyarakat sebagai pelanggan air minum. Hal ini untuk menjamin kepastian akan kuantitas, kualitas dan kontinuitas pengaliran. Pendistribusian air minum dapat dilakukan dengan ( Masduqi dan Assomadi, 2012) :

- Sistem perpipaan, yaitu pendistribusian air minum melalui jaringan pipa distribusi hingga ke pelanggan. Untuk pendistribusian menggunakan perpipaan ini dapat dilakukan dengan pemompaan atau pengaliran secara gravitasi. Hal ini tergantung pada perbedaan elevasi antara unit produksi dengan daerah pelayanan.

- Sistem non-perpipaan, yaitu pendistribusian air minum tidak melalui jaringan pipa distribusi, melainkan menggunakan alat transportasi untuk mengangkut air dari unit produksi menuju ke pelanggan, seperti mobil tangki, gerobak dorong, dan lain-lain.

\section{Sistem Jaringan Induk dan Perpipaan Distribusi Air}

Jaringan pipa induk merupakan pipa distribusi yang memilik diameter terbesar sehingga jangkauan pelayanannya luas. Secara fisik pipa induk dapat mengalirkan air sampai akhir tahap perencanaan dengan debit jam puncak, memiliki ketahanan yang tinggi namun tidak melayani penyadapan langsung ke konsumen (Dirjen Cipta Karya, 2009). Sistem jaringan induk perpipaan yang dipakai dalam mendistribusikan air bersih terdiri atas dua sistem yaitu (Al-Layla,1980):

a. Sistem Cabang (Branch System). Pada sistem ini, air hanya mengalir dari satu arah dan pada setiap ujung pipa akhir daerah pelayanan terdapat titik akhir (dead end). Pipa distribusi tidak saling berhubungan, area pelayanan disuplai air melalui satu jalur pipa utama.

b. Sistem Melingkar (Loop System) Pada sistem ini, pipa induk distribusi saling berhubungan satu dengan yang lain membentuk jaringan melingkar (loop) sehingga pada pipa induk tidak ada titik mati dan air akan mengalir ke suatu titik yang dapat melalui beberapa arah dengan tekanan yang relatif stabil.

c. Sistem Kombinasi (Combination System) Sistem jaringan perpipaan kombinasi merupakan gabungan dari sistem jaringan perpipaan bercabang (Branching System) dan sistem melingkar (LoopSystem). Sistem distribusi adalah jaringan perpipaan untuk mengalirkan air minum dari reservoir menuju daerah pelayanan/ konsumen (Al-Layla,1980). Perencanaan sistem distribusi air minum didasarkan atas dua faktor utama yaitu kebutuhan air (water demand) dan tekanan air, serta ditunjang dengan faktor kontinuitas dan safety (keamanan).

\section{Intake dan Jaringan Pipa Transmisi}

Intake adalah bangunan penangkap air atau tempat air masuk dari sungai, danau atau sumber air permukaan lainnya ke instalasi pengolahan. Bangunan intake ini berfungsi sebagai bangunan pertama untuk masuknya air dari sumber air. Pada umumnya, sumber air untuk pengolahan air bersih, diambil dari sungai. Pada bangunan intake ini biasanya terdapat bar screen yang berfungsi untuk menyaring benda-benda yang ikut tergenang dalam air. Selanjutnya, air akan masuk ke dalam sebuah bak yang nantinya akan dipompa 
ke bangunan selanjutnya, yaitu WTP - Water Treatment Plant (Dirjen Cipta Karya, 2009). Jaringan pipa transmisi adalah jalur pipa pembawa air bersih dari titik awal transmisi air bersih ke titik akhir transmisi air bersih. Fungsi transmisi (transmission) adalah mengalirkan air dari sumbernya (collection system) ke awal sistem distribusi. Jarak antara sumber air dan sistem distribusi boleh jadi berkilokilometer tetapi bisa juga dekat. Kualitas air yang ditransmisikannya bisa berupa air baku, bisa juga air bersih (olahan, baik setengah diolah maupun sudah selesai diolah).

\section{Reservoir}

Sebelum didistribusikan, air masuk ke dalam reservoir. Reservoir ini berfungsi sebagai tempat penampungan sementara air bersih sebelum didistribusikan melalui pipa-pipa secara grafitasi. Reservoir ini biasanya diletakkan di tempat dengan elevasi lebih tinggi daripada tempat-tempat yang menjadi sasaran distribusi. Biasanya terletak di atas bukit atau gunung. Setelah dari reservoir, air bersih siap untuk didistribusikan melalui pipa-pipa dengan berbagai ukuran ke tiap daerah distribusi. Jenis reservoir meliputi (Dirjen Cipta Karya, 2009) :

a. Ground reservoir yaitu bangunan. penampung air bersih di bawah permukaan tanah.

b. Elevated reservoir adalah bangunan penampung air yang terletak di atas permukaan tanah dengan ketinggian tertentu sehingga tekanan air pada titik terjauh masih tercapai.

\section{Pompa}

Pompa merupakan salah satu alat yang berperan penting dalam proses pengolahan air . Berfungsi mendistribusikan air dari sumber air ke tempat pengolahan air, menyalurkan air ke konsumen dan sebagainya. Jenis-jenis pompa air pun sangat banyak tergantung dari kegunaannya. Di dalam penyediaan air bersih pompa digunakan pada intake, sumur pengumpul, unit treatment, sistem distibusi dengan memakai pompa jenis sentrifugal. Pompa dibutuhkan untuk dapat memberikan head tertentu dan untuk menghantarkan kuantitas air.

\section{Kehilangan Air}

Dalam suatu perencanaan perpipaan, kebocoran pipa tidak dapat dihindari. Kehilangan air bersifat teknis. Besarnya kehilangan air harus diperhatikan dengan tujuan agar titik- titik pelayanan tetap dapat terbutuhi kebutuhan airnya. Kehilangan air didefinisikan sebagai jumlah air yang hilang akibat (Dirjen Cipta Karya, 2009) :

a. Pemasangan sambungan yang tidak tetap.

b. Terkena tekanan dari luar sehingga menyebabkan pipa retak atau pecah.

c. Penyambungan liar.

Untuk mengetahui jika terjadi kebocoran yang tidak tepat misalnya air rembesan dari keretakan pipa, dapat diatasi dengan alat pendeteksi kebocoran yang disebut Leak detector. Sedangkan upaya untuk mengurangi terjadinya kehilangan air yang lebih besar dalam perencanaan sistem distribusi air dilakukan pembagian wilayah atau zoning untuk memudahkan pengontrolan kebocoran pipa,serta pemasangan meteran air. Kebocoran yang terjadi dalam pengelolaan sistem penyediaan air minum PDAM dikelompokkan dalam 2 jenis yaitu:

\section{Kebocoran Secara Fisik}

Adalah hilangnya sejumlah air minum pada proses penyediaan, pendistribusian dan pelayanan air minum PDAM yang diperlihatkan oleh adanya aliran air secara fisik yang keluar dari sistem jaringan pipa distribusi dan pelayanan PDAM. Penyebab terjadinya kebocoran secara fisik yaitu:

1. Faktor Teknis, antara lain :

a. Kebocoran air pada pipa distribusi dan perlengkapannya .

b. Kebocoran air pada pipa dinas dan komponen instalasi SL sebelum meter air.

c. Penggunaan fire hydrant, pengurasan jaringan pipa, penggunaan air instalasi produksi.

2. Faktor Non Teknis, antara lain :

a. Sambungan tidak terdaftar/illegal.

b. Pencurian air.

c. Kecurangan pelanggan (pemasangan pipa by-pass di instalasi Sambungan Rumah).

\section{Kebocoran Non Fisik}

Adalah hilangnya sejumlah air minum pada proses pendistribusian dan pelayanan air minum kepada pelanggan PDAM yang tidak diperlihatkan oleh adanya aliran air secara fisik 
yang keluar dari sistem jaringan pipa distribusi dan pelayanan PDAM. Penyebab terjadinya Kebocoran non fisik yaitu:

a. Faktor Teknis, antara lain :

- Meter air tidak akurat

b. Faktor Non Teknis, antara lain :

- Kesalahan pembacaan angka pada meter air SL

- Kesalahan pencatatan hasil pembacaan meter air SL

- Kesalahan perhitungan hasil pembacaan meter air SL

- Hasil pembacaan meter air SL yang diperkirakan

- Meter air SL tidak dibaca

- Kecurangan pelanggan (meter air ditempel magnit, ditusuk jarum, ditetesi larutan garam, dimiringkan, dibalik dsb.).

Adapun terjadinya Kebocoran secara fisik dan non fisik pada proses pendistribusian dan pelayanan air minum PDAM disebabkan oleh faktor-faktor sebagai berikut:

1. Faktor penyebab kebocoran secara fisik

a. Kualitas material yang digunakan kurang baik

b. Pekerjaan pemasangan pipa kurang baik

c. Pekerjaan galian dan penimbunan kembali pipa tidak memenuhi syarat

d. Tekanan air pada sistem jaringan pipa terlalu tinggi Umur material telah melewati batas umur teknisnya

2. Faktor penyebab kebocoran secara non fisik

Kemampuan petugas pembaca meter air SL rendah dan Pengetahuan pelanggan PDAM rendah serta Penerapan peraturan belum dilakukan/tidak tegas.

\section{TUJUAN DAN LINGKUP ANALISIS}

\section{TUJUAN ANALISIS}

Tujuan kajian ini antara lain adalah Seberapa besar tingkat kehilangan air dan kerugian PDAM akibat kehilangan air pada sistem distribusi air bersih PDAM Tirta Bukae wilayah Kec. Masamba antara tahun 2017-2018 dan faktor apa saja yang dapat mempengaruhi meningkatnya tingkat kehilangan air PDAM tersebut, sehingga mampu memecahkan permasalahan diwilayah tersebut.

\section{LINGKUP ANALISIS}

Kajian tingkat kehilangan air dan kerugian PDAM Tirta Bukae wilayah Kec.

Masamba mencakup kajian sebagai berikut :

1. Keakuratan meter pelanggan,

2. Perhitungan volume suplai air,

3. Perhitungan kehilangan air komersial,

4. Perhitungan tarif rata-rata 1 tahun,

5. Perhitungan biaya akibat kehilangan air.

\section{HASIL DAN PEMBAHASAN}

\section{A. Data Eksisting atau Data Sekunder}

Jumlah wilayah yang terlayani oleh PDAM Tirta Bukae Luwu utara adalah 6 wilayah diantaranya kec. Masamba, kec. Mappadeceng, kec. Bonebone, kec. Baebunta, Sukamaju dan Tanalili. Total pelanggan tahun 2017 sebesar 4.600 pelanggan dan untuk tahun 2018 sebesar 6.313 pelanggan. Total wilayah pelanggan dan jumlah pelanggan dapat di lihat pada tabel 1 .

Tabel 1

Jumlah pelanggan PDAM Tirta Bukae Luwu

Utara Kec.Masamba Tahun 2017-2018

\begin{tabular}{|c|c|c|c|}
\hline \multirow[b]{2}{*}{ NO } & \multirow[b]{2}{*}{ wilayah } & \multicolumn{2}{|c|}{ jumlah pelanggan } \\
\hline & & 2017 & 2018 \\
\hline 1 & Masamba & 2.407 & 2.863 \\
\hline 2 & Mappadeceng & 508 & 480 \\
\hline 3 & Bone-bone & 969 & 1.328 \\
\hline 4 & Baebunta & 469 & 718 \\
\hline 5 & Sukamaju & 247 & 611 \\
\hline 6 & Tanalili & - & 313 \\
\hline & Total & 4.600 & 6.313 \\
\hline
\end{tabular}

Sumber : PDAM Tirta Bukae tahun 2017-2018

Dari tabel 1 mengambil sampel dari kec. Masamba yang melayani 9 wilayah dengan total pelanggan 2017 sebanyak 2.407 dan 2018 sebanyak 2.863. total pelanggan yang di layani oleh PDAM Tirta Bukae Luwu Utara Kec.Masamba dapat dilihat pada tabel 2.

Tabel 2

Cakupan wilayah yang terlayani PDAM Tirta Bukae

Luwu Utara untuk kec.Masamba Tahun 20172018

\begin{tabular}{|c|l|c|c|}
\hline \multirow{2}{*}{ Wilayah } & Cakupan & 2017 & 2018 \\
\cline { 3 - 4 } & $\begin{array}{c}\text { jumlah } \\
\text { pelanggan }\end{array}$ & $\begin{array}{c}\text { jumlah } \\
\text { pelanggan }\end{array}$ \\
\hline I & Baliase & 534 & 579 \\
\hline
\end{tabular}




\begin{tabular}{|c|l|c|c|}
\hline II & Baloli & 98 & 124 \\
\hline III & Bone & 315 & 364 \\
\hline IV & Bone Tua & 487 & 512 \\
\hline V & Kamiri & 113 & 129 \\
\hline VI & Kappuna & 725 & 756 \\
\hline VII & Laba & 109 & 167 \\
\hline VIII & Lapapa & 23 & 25 \\
\hline IX & Pandak & 3 & 4 \\
\hline & Total & $\mathbf{2 . 4 0 7}$ & $\mathbf{2 . 6 6 0}$ \\
\hline
\end{tabular}

Sumber :PDAM Tirta Bukae

Dari 9 wilayah yang terlayani PDAM Tirta Bukae untuk kecamatan Masamba terbagi dengan jenis pelanggan yang dapat dilihat pada tabel 3

Tabel 3

Jenis pelanggan PDAM Tirta Bukae Luwu Utara

\begin{tabular}{|c|c|c|c|}
\hline \multirow[b]{2}{*}{ no } & \multirow[b]{2}{*}{ jenis langganan } & \multicolumn{2}{|c|}{ jumlah } \\
\hline & & 2017 & 2018 \\
\hline 1 & sosial umum & 73 & 80 \\
\hline 2 & rumah tangga & 2.088 & 2.504 \\
\hline 3 & $\begin{array}{l}\text { instansi } \\
\text { pemerintah }\end{array}$ & 34 & 38 \\
\hline 4 & niaga besar & - & 10 \\
\hline 5 & niaga kecil & 212 & 231 \\
\hline & total & 2.407 & 2.407 \\
\hline
\end{tabular}

Kec.Masamba Tahun 2017-2018

Sumber : PDAM Tirta Bukae Luwu Utara kec. Masamba tahun 2017-2018

\section{Volume produksi air}

Volume produksi air adalah air yang diproduksi oleh PDAM Tirta Bukae Luwu Utara kec. Masamba yang ditunjukkan pada Tabel 4 dan 5 . Total volume produksi air bersih pada tahun 2017 yaitu 1.306.305 m3/tahun dan tahun 2018 yaitu $1.470 .533 \mathrm{~m} 3 /$ tahun. Jumlah produksi PDAM Tirta Bukae Luwu Utara wilayah kec. Masamba tahun 2017-2018 dapat dilihat pada tabel 4 dan 5.

Tabel 4 dan 5

Jumlah produksi dan distribusi PDAM Tirta

Bukae untuk kec.Masamba

Tabel 4

Tahun 2017

\begin{tabular}{|c|c|c|}
\hline $\begin{array}{c}\text { bulan } \\
\text { ke- }\end{array}$ & $\begin{array}{c}\text { volume } \\
\text { produksi } \\
(\mathbf{m 3})\end{array}$ & $\begin{array}{c}\text { volume } \\
\text { distribusi } \\
(\mathbf{m 3})\end{array}$ \\
\hline 1 & 99.958 & 97.570 \\
\hline 2 & 84.975 & 82.710 \\
\hline
\end{tabular}

tabel 5

tahun 2018

\begin{tabular}{|c|c|c|}
\hline $\begin{array}{c}\text { bulan } \\
\text { ke- }\end{array}$ & $\begin{array}{c}\text { volume } \\
\text { produksi } \\
(\mathbf{m} 3)\end{array}$ & $\begin{array}{c}\text { volume } \\
\text { distribusi } \\
(\mathbf{m} 3)\end{array}$ \\
\hline 1 & 113.662 & 112.360 \\
\hline 2 & 129.616 & 128.440 \\
\hline
\end{tabular}

\begin{tabular}{|c|c|c|}
\hline 3 & 102.680 & 100.670 \\
\hline 4 & 107.388 & 104.970 \\
\hline 5 & 108.688 & 106.550 \\
\hline 6 & 109.337 & 107.310 \\
\hline 7 & 118.866 & 116.680 \\
\hline 8 & 112.587 & 110.660 \\
\hline 9 & 114.968 & 112.930 \\
\hline 10 & 116.307 & 114.580 \\
\hline 11 & 110.628 & 108.540 \\
\hline 12 & 119.978 & 117.640 \\
\hline total & $\mathbf{1 . 3 0 6 . 3 0 5}$ & $\mathbf{1 . 2 8 0 . 8 1 0}$ \\
\hline
\end{tabular}

\begin{tabular}{|c|c|c|}
\hline 3 & 113.459 & 112.250 \\
\hline 4 & 122.670 & 121.410 \\
\hline 5 & 123.913 & 122.890 \\
\hline 6 & 123.260 & 122.180 \\
\hline 7 & 125.298 & 124.120 \\
\hline 8 & 124.784 & 123.420 \\
\hline 9 & 112.650 & 111.180 \\
\hline 10 & 128.760 & 133.490 \\
\hline 11 & 134.513 & 127.920 \\
\hline 12 & 117.948 & 116.770 \\
\hline total & $\mathbf{1 . 4 7 0 . 5 3 3}$ & $\mathbf{1 . 4 5 6 . 4 3 0}$ \\
\hline
\end{tabular}

Sumber : PDAM Tirta Bukae Luwu Utara

kec. Masamba Tahun 2017-2018

Tabel 6

Total Konsumsi Resmi Berekening PDAM Tirta Bukae Tahun2017

\begin{tabular}{|c|c|c|c|c|}
\hline \multicolumn{5}{|c|}{2017} \\
\hline \multirow[t]{2}{*}{$\begin{array}{l}\text { bulan } \\
\text { ke }\end{array}$} & \multicolumn{2}{|c|}{$\begin{array}{c}\text { volume penjualan } \\
\left(\mathbf{m}^{3}\right)\end{array}$} & \multicolumn{2}{|c|}{ pendapatan (Rp) } \\
\hline & SR & $\begin{array}{l}\text { MOBIL } \\
\text { TANGKI }\end{array}$ & SR & $\begin{array}{c}\text { MOBIL } \\
\text { TANGKI }\end{array}$ \\
\hline 1 & 65.026 & 1.280 & 146.170 .000 & 2.877 .000 \\
\hline 2 & 55.201 & 534 & 124.085 .000 & 1.220 .000 \\
\hline 3 & 64.818 & 1.235 & 145.702 .000 & 2.776 .000 \\
\hline 4 & 68.492 & 756 & 153.961 .000 & 1.699 .000 \\
\hline 5 & 68.896 & 769 & 154.869 .000 & 1.729 .000 \\
\hline 6 & 69.446 & 814 & 156.106 .000 & 1.830 .000 \\
\hline 7 & 78.385 & 916 & 176.253 .000 & 2.059 .000 \\
\hline 8 & 71.308 & 1.015 & 160.291 .000 & 2.282 .000 \\
\hline 9 & 76.092 & 1.756 & 171.045 .000 & 3.947 .000 \\
\hline 10 & 74.241 & 876 & 166.884 .000 & 1.969 .000 \\
\hline 11 & 70.429 & 547 & 158.315 .000 & 1.229 .000 \\
\hline 12 & 76.337 & 956 & 171.560 .000 & 2.149 .000 \\
\hline total & 838.663 & 11.463 & 1.885.205.930 & 25.767 .341 \\
\hline
\end{tabular}

Sumber : PDAM Tirta Bukae Luwu Utara

kec. Masamba Tahun 2017

Tabel 7

Total Konsumsi Resmi Berekening PDAM Tirta Bukae Tahun2018

\begin{tabular}{|c|c|c|c|c|}
\hline \multicolumn{5}{|c|}{2018} \\
\hline \multirow[t]{2}{*}{ bulan ke } & \multicolumn{2}{|c|}{$\begin{array}{c}\text { volume penjualan } \\
\left(\mathbf{m}^{\mathbf{3}}\right)\end{array}$} & \multicolumn{2}{|c|}{ pendapatan (Rp) } \\
\hline & SR & $\begin{array}{c}\text { MOBIL } \\
\text { TANGKI }\end{array}$ & SR & $\begin{array}{c}\text { MOBIL } \\
\text { TANGKI }\end{array}$ \\
\hline 1 & 73.620 & 2.018 & 189.902 .000 & 5.208 .000 \\
\hline 2 & 85.25 & 1.345 & 219.902 .000 & 3.459 .000 \\
\hline 3 & 74.219 & 1.092 & 191.447 .000 & 2.817 .000 \\
\hline 4 & 78.922 & 1.456 & 203.579 .000 & 3.756 .000 \\
\hline 5 & 79.508 & 1.348 & 205.090 .000 & 3.477 .000 \\
\hline
\end{tabular}




\begin{tabular}{|c|c|c|c|c|}
6 & 78.643 & 2.567 & 202.859 .000 & 6.621 .000 \\
\hline 7 & 80.061 & 1.980 & 206.517 .000 & 5.107 .000 \\
\hline 8 & 79.813 & 1.870 & 205.877 .000 & 4.824 .000 \\
\hline 9 & 73.585 & 987 & 189.812 .000 & 2.546 .000 \\
\hline 10 & 87.943 & 1.348 & 226.848 .000 & 3.477 .000 \\
\hline 11 & 84.705 & 1.036 & 218.496 .000 & 2.672 .000 \\
\hline 12 & 75.923 & 956 & 195.842 .000 & 2.466 .000 \\
\hline Total & $\mathbf{9 5 2 . 1 9 7}$ & $\mathbf{1 8 . 0 0 3}$ & $\mathbf{2 . 4 5 6 . 1 8 1 . 0 0 0}$ & $\mathbf{4 6 . 4 3 0 . 0 0 0}$ \\
\hline
\end{tabular}

Sumber : PDAM Tirta Bukae Luwu Utara

kec. Masamba Tahun 2018

2. Konsumsi Resmi Berekening

Konsumsi resmi berekening ialah konsumsi resmi air atau volume pemakaian air oleh pelanggan yang dapat direkeningkan. Konsumsi resmi berekening terdiri atas konsumsi bermeter berekening yang bersumber dari pelanggan rumah tangga dan konsumsi tak bermeter berekening yang bersumber dari penjualan mobil tangki yang ditunjukkan Tabel 6 dan 7. Konsumsi resmi berekening merupakan volume air yang terjual ditambah biaya dana meter dan administrasi. Total volume penjualan air untuk sambungan rumah tangga pada tahun 2017 sebesar 838.663 m3/tahun dan untuk mobil tangki sebesar $11.463 \mathrm{~m} 3 /$ tahun dan pada tahun 2018 sebesar $952.197 \mathrm{~m} 3 /$ tahun dan untuk mobil tangki sebesar 18.003 m3/tahun .

- Konsumsi Resmi Tak Berekening

Konsumsi resmi tak berekening dibagi menjadi dua, yaitu konsumsi bermeter tak berekening dan konsumsi tak bermeter tak berekening. Konsumsi bermeter tak berekening merupakan banyaknya konsumsi air pada instansiinstansi yang dibebaskan dari pembayaran. Sedangkan konsumsi tak bermeter tak berekening merupakan banyaknya pemakaian air yang didistribusikan melalui tangki air PDAM untuk keperluan umum. Komponen data neraca air ini tidak tersedia pada PDAM Tirta Bukae Luwu Utara Kec.Masamba karena semua penggunaan air di PDAM Tirta Bukae Luwu Utara Kec.Masamba tidak ada yang dibebaskan pembayarannya.
- Tarif Harga Air

Tarif rata-rata didapatkan dari pembagian pendapatan selama satu tahun dengan pemakaian atau penjualan air selama satu tahun ditunjukkan pada Tabel 8.

Tabel 8.

Rekapitulasi Total Jumlah Air Terjual dan Total Pendapatan tahun 2017-2018

\begin{tabular}{|c|c|c|c|c|c|}
\hline \multicolumn{3}{|c|}{2017} & \multicolumn{3}{|c|}{2018} \\
\hline $\begin{array}{c}\text { bulan } \\
\text { ke }\end{array}$ & $\begin{array}{c}\text { volume } \\
\text { penjualan } \\
\left(\mathrm{m}^{3}\right)\end{array}$ & $\begin{array}{c}\text { pendapatan } \\
\text { (Rp) }\end{array}$ & $\begin{array}{c}\text { bulan } \\
\text { ke }\end{array}$ & $\begin{array}{c}\text { volume } \\
\text { penjualan } \\
\left(\mathbf{m}^{3}\right)\end{array}$ & $\begin{array}{c}\text { pendapatan } \\
\text { (Rp) }\end{array}$ \\
\hline 1 & 66.306 & 149.047 .000 & 1 & 75.638 & 228.100 .000 \\
\hline 2 & 55.735 & 125.305 .000 & 2 & 86.595 & 243.682 .000 \\
\hline 3 & 66.053 & 148.478 .000 & 3 & 75.311 & 213.216 .000 \\
\hline 4 & 69.248 & 155.660 .000 & 4 & 80.378 & 217.020 .000 \\
\hline 5 & 69.665 & 156.598 .000 & 5 & 80.856 & 226.897 .000 \\
\hline 6 & 70.260 & 157.936 .000 & 6 & 81.210 & 229.144 .000 \\
\hline 7 & 79.301 & 178.312 .000 & 7 & 82.041 & 231.387 .000 \\
\hline 8 & 72.323 & 162.573 .000 & 8 & 81.683 & 230.421 .000 \\
\hline 9 & 77.848 & 174.992 .000 & 9 & 74.572 & 211.221 .000 \\
\hline 10 & 75.117 & 168.853 .000 & 10 & 89.291 & 252.582 .000 \\
\hline 11 & 70.976 & 159.544 .000 & 11 & 85.741 & 241.378 .000 \\
\hline 12 & 77.293 & 173.709 .000 & 12 & 76.879 & 217.451 .000 \\
\hline total & 850.126 & 1.910.973.271 & total & 970.195 & 2.502.611.000 \\
\hline
\end{tabular}

Sumber : PDAM Tirta Bukae Luwu Utara Tahun 2017-2018

\section{B. Data primer}

1. Analisa Kehilangan Air

Tingkat kehilangan air dihitung persentasenya berdasarkan selisih antara jumlah air yang didistribusikan $\left(\mathrm{m}^{3}\right)$ dengan jumlah air yang tercatat dalam rekening sehingga air tidak terbayarkan atau tidak terkonversi sebagai rupiah. Rumus untuk menghitung kehilangan air sebagai berikut.

Kehilangan air $=$ Lair distribusi - Lair terjual (dalam $\mathrm{m}^{3} /$ waktu - bulan atau tahun)

$$
\text { kehilanganAir }(\%)=\frac{\text { kehilanganAir }}{\text { AirDistribusi }} \times 100 \%
$$

Dimana: Air terjual = air yang dibayar oleh pelanggan pada bulan atau Kumulatif dalam satu tahun $\left(\mathrm{m}^{3}\right)$

Kehilangan air PDAM Tirta Bukae Luwu Utara pada tahun 2018 disajikan pada Tabel 9 dan 10. 
Tabel 9

Kehilangan Air PDAM Tirta Buka Luwu Utara kec.Masamba Tahun 2017

\begin{tabular}{|c|c|c|c|c|}
\hline $\begin{array}{c}\text { bulan } \\
\text { ke- }\end{array}$ & $\begin{array}{c}\text { volume } \\
\text { distribusi } \\
\left(\mathbf{m}^{\mathbf{3}} / \mathbf{b u l a n}\right)\end{array}$ & $\begin{array}{c}\text { air terjual } \\
\left(\mathbf{m}^{\mathbf{3}} \mathbf{\text { /bulan}}\right)\end{array}$ & $\begin{array}{c}\text { kehilangan air } \\
\left(\mathbf{m}^{\mathbf{3}} / \mathbf{b u l a n}\right)\end{array}$ & $\%$ \\
\hline 1 & 97.570 & 66.306 & 42.264 & $43.31 \%$ \\
\hline 2 & 82.710 & 55.735 & 26.975 & $32.61 \%$ \\
\hline 3 & 100.670 & 66.053 & 34.617 & $34.28 \%$ \\
\hline 4 & 104.970 & 69.248 & 35.722 & $34.03 \%$ \\
\hline 5 & 106.550 & 69.665 & 36.885 & $34.61 \%$ \\
\hline 6 & 107.310 & 70.26 & 37.050 & $34.52 \%$ \\
\hline 7 & 116.680 & 79.301 & 37.379 & $32.03 \%$ \\
\hline 8 & 110.660 & 72.323 & 38.337 & $34.64 \%$ \\
\hline 9 & 112.930 & 77.848 & 35.082 & $31.06 \%$ \\
\hline 10 & 114.580 & 75.117 & 39.463 & $34.44 \%$ \\
\hline 11 & 108.540 & 70.976 & 37.564 & $34.6 \%$ \\
\hline 12 & 117.640 & 77.293 & 40.347 & $34.29 \%$ \\
\hline total & $\mathbf{1 . 2 8 0 . 8 1 0}$ & $\mathbf{8 5 0 . 1 2 6}$ & $\mathbf{4 3 0 . 6 8 4}$ & $\mathbf{3 4 . 5 3 \%}$ \\
\hline & $54 m 6 \%$ & $\mathrm{nalis}$ & & \\
\hline
\end{tabular}

Sumber : Analis data sekunder.

Tabel 10

Kehilangan Air PDAM Tirta Buka Luwu

Utara kec.Masamba Tahun 2018

\begin{tabular}{|c|c|c|c|c|}
\hline $\begin{array}{c}\text { bulan } \\
\text { ke- }\end{array}$ & $\begin{array}{c}\text { volume } \\
\text { distribusi } \\
\left(\mathbf{m}^{\mathbf{3}} / \mathbf{b u l a n}\right)\end{array}$ & $\begin{array}{c}\text { air terjual } \\
\left(\mathbf{m}^{\mathbf{3}} / \text { bulan }\right)\end{array}$ & $\begin{array}{c}\text { kehilangan } \\
\text { air } \\
\left(\mathbf{m}^{\mathbf{3}} / \mathbf{b u l a n}\right)\end{array}$ & $\%$ \\
\hline 1 & 112.360 & 75.638 & 36.722 & $32.68 \%$ \\
\hline 2 & 128.440 & 86.595 & 41.845 & $32.58 \%$ \\
\hline 3 & 112.250 & 75.311 & 36.939 & $32.91 \%$ \\
\hline 4 & 121.410 & 80.378 & 41.032 & $33.80 \%$ \\
\hline 5 & 122.890 & 80.856 & 42.034 & $34.20 \%$ \\
\hline 6 & 122.180 & 81.210 & 40.970 & $33.53 \%$ \\
\hline 7 & 124.120 & 82.041 & 42.079 & $33.90 \%$ \\
\hline 8 & 123.420 & 81.683 & 41.737 & $33.82 \%$ \\
\hline 9 & 111.180 & 74.572 & 36.608 & $32.93 \%$ \\
\hline 10 & 133.490 & 89.291 & 44.199 & $33.11 \%$ \\
\hline 11 & 127.920 & 85.741 & 42.179 & $32.97 \%$ \\
\hline 12 & 116.770 & 76.879 & 39.891 & $34.16 \%$ \\
\hline total & $\mathbf{1 . 4 5 6 . 4 3 0}$ & $\mathbf{9 7 0 . 1 9 5}$ & $\mathbf{4 8 8 . 2 3 5}$ & $\mathbf{3 3 . 5 2 \%}$ \\
\hline & & &
\end{tabular}

Sumber: Analis data sekunder.

2. Kerugian akibat kehilangan air.

Total kerugian PDAM Tirta Bukae Luwu Utara kec.Masamba jika dikalikan dengan ratarata harga air per $\mathrm{m}^{3}$ sebesar Rp. 2.570 maka total kerugian PDAM tahun 2017 dengan kehilangan air sebersar $430.684 \mathrm{~m}^{3} /$ tahun adalah Rp. 1.110.734.036 pertahun dan tahun 2018 dengan kehilangan air sebesar 488.235 $\mathrm{m}^{3} /$ tahun adalah Rp. 1.259.158.065 pertahun. Total kerugian PDAM Tirta Bukae kec.Masamba dapat dilihat pada tabel 11.

Tabel 11

Konvesi kehilangan air

\begin{tabular}{c|c|c|}
\multirow{4}{*}{ NRW } & \multicolumn{2}{|c|}{ TAHUN } \\
\cline { 2 - 3 } Harga (Rp) & 2017 & 2018 \\
\cline { 2 - 3 } 2.579 & \multicolumn{2}{|c|}{ Kehilangan air $\left(\mathrm{m}^{3} /\right.$ tahun $)$} \\
\cline { 2 - 3 } & 430.684 & 488.235 \\
\cline { 2 - 3 } & \multicolumn{2}{|c|}{ kerugian(Rp/tahun) } \\
\cline { 2 - 3 } & 1.110 .734 .036 & 1.259 .158 .065 \\
\hline
\end{tabular}

Sumber : Analisa data

Grafik tingkat kehilangan air PDAM Tirta

Bukae Kec.Masamba tahun 2017-2018

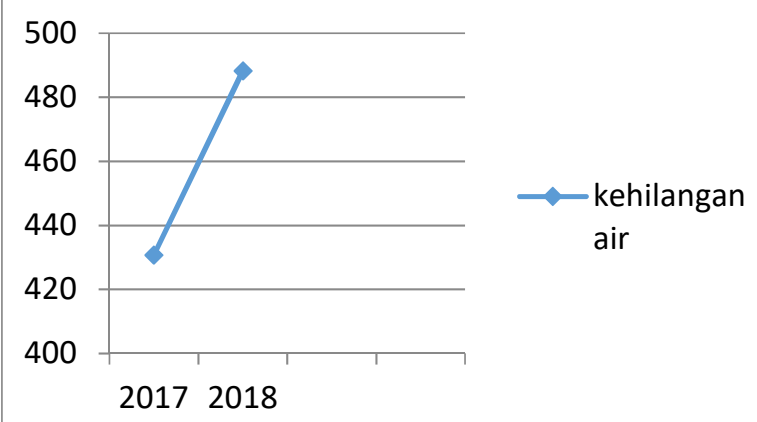

Pada grafik terlihat meningkatnya kehilangan air dari tahun 2017-2018 dengan jumlah kehilangan air tahun 2017 mencapai 430.684 $\mathrm{m}^{3} /$ tahun dan 2018 mencapai 488.235 $\mathrm{m}^{3} /$ tahun.

3. Faktor tingkat kehilangan air

Dari proses wawancara dengan pihak PDAM Luwu Utara dan pelanggan PDAM Luwu Utara Faktor yang mempengaruhi tingkat kehilangan air adalah:

1. Penyebab tingkat kehilangan air (ATR)

a. Teknis: illegal connection: pencurian umum, pipa/ sambungan illegal, meteran: macet, masih analog sehingga angka tertera pada water meter tidak sesuai, pipa sambungan yang terlalu tua dan tidak terstandarisasi.

b. Non teknis: rendahnya komitmen dari pimpinan manajemen, pengadaan: tidak ada dana, tidak ada Standard Operation Procedur dan tidak ada manajemen aset, dari aspek sumber daya manusia: kesalahan membaca water meter pelanggan, kurang responsifnya pengelola dalam memberikan penanganan kerusakan, ditemui pegawai yang tidak pernah mendapatkan sosialisasi penanganan ATR, 
sistem kebijakan: PDAM tidak merasa dirugikan atau diuntungkan dari tinggi rendahnya ATR, administrasi: kesalahan dalam menginput data, Fraud: terjadi konspirasi pelanggan dan petugas meteran.

\section{Upaya dalam Mengatasi ATR}

Strategi dan tindak lanjut untuk mengatasi ATR yang dapat dirumuskan untuk mengatasi masalah ATR, adalah:

a. Jaringan, karena perencanaan jaringan pipa PDAM yang tidak baik, serta dokumentasi as build drawing yang tidak lengkap, maka perlu dilakukan audit jaringan yang disinkronkan dengan rekening wilayah, paling tidak dua tahun sekali, dan mengoptimalkan fungsi district meter area.

b. Pipa: standarisasi dan simplifikasi varian pipa, melalui (pengadaan)

c. Meteran: kalibrasi, penggantian berkala, isu investasi, kebijakan yang memberikan insentif ganti meteran dan punishment. Strategi komunikasi untuk program penggantian meter sehingga konflik menjadi rendah.

d. Komersial: modernisasi sistem komersial PDAM yang di dalamnya termasuk: billing management, asset management, realibility management, service management dengan proses bisnis yang diotomasi untuk menjamin lebih cepat, lebih murah, lebih baik, lebih aman, transparan dan akuntabel

5. Rekomendasi menurunkan tingkat kehilangan air.

Rekomendasi untuk menurunkan tingkat kehilangan air PDAM Tirta Bukae Luwu Utara Temuan-temuan berikut ini ialah data penunjang yang digunakan sebagai pertimbangan dalam menentukan strategi penurunan kehilangan air yaitu:

a. Pembacaan meter air

PDAM Tirta Bukae telah melakukan pembacaan meter air dengan menggunakan alat komunikasi (HP) yang telah terinstall dengan software sehingga pembacaan dapat dilakukan dengan sistem barcode. Namun, tidak semua pembacaan meter air dilakukan menggunakan alat komunikasi tersebut.

b. Jenis meter air yang dipasang tidak sesuai Adanya beberapa meter air yang seharusnya digunakan untuk kelompok industri, pelabuhan, niaga besar, dan sejenisnya digunakan oleh rumah tangga.

c. Kontinuitas aliran

Menurut laporan PDAM Tirta Bukae Luwu Utara kec.Masamba jam operasional kinerja IPAM masih sangat rendah yaitu hanya 15 jam/hari

6. Penurunan tingkat kehilangan air

Penurunan kehilangan air pada PDAM Tirta Bukae Kec. Masamba difokuskan pada penurunan kehilangan air komersial karena relatif lebih murah dan mudah dalam pelaksanaannya. Adapun strategi yang direkomendasikan untuk menangani kehilangan air komersial pada PDAM Tirta Bukae Kec. Masamba ialah:

a. Penggantian meter air pelanggan baik meter air dengan penyimpangan positif maupun negatif. Meter air yang digunakan ialah meter air kelas B yang tidak berumur lebih dari 6 tahun dan meter air kelas $C$ yang tidak berumur lebih dari 3 tahun. Meter air yang digunakan juga harus sesuai dengan kelompok pelanggan yang menggunakan berdasarkan SNI 2547:2008 tentang Spesifikasi Meter Air

b. Dilakukan kalibrasi pada meter air pelanggan karena penyimpangan pembacaan meter air memberikan kontribusi terhadap kehilangan air PDAM dan kerugian pada pihak pelanggan.

c. Penerapan sistem pembacaan meter air pelanggan menggunakan alat komunikasi (HP) secara menyeluruh.

d. Membentuk tim penertiban sambungan liar di berbagai titik kemudian melakukan penggalian agar menjadi barang bukti untuk tindakan selanjutnya berupa pendendaan atau pemberkasan ke kepolisian.

e. Pemasangan water meter pada jaringan transmisi dan distribusi.

f. Membuat pemetaan jaringan menggunakan GIS (Geographic Information Systems).

g. Membentuk tim pengendalian NRW yang bersifat tetap dan terstruktur yang bertugas.

h. Pencarian kebocoran secara aktif baik kebocoran fisik melalui step test dan kebocoran non fisik. 


\section{A. KESIMPULAN}

\section{KESIMPULAN DAN SARAN}

1. Jumlah pelanggan yang terlayani oleh PDAM Tirta Bukae Luwu Utara Kec.Masamba tahun 2017 sebanyak 2.407 pelanggan dan tahun 2018 mengalami peningkatan dengan jumlah pelanggan sebanyak 2.660 pelanggan dengan jumlah volume produksi PDAM Tirta Bukae Luwu Utara Kec.Masamba tahun 2017 sebesar $1.306 .305 \mathrm{~m}^{3}$ dan tahun 2018 sebesar 1.470.533 $\mathrm{m}^{3}$, Volume distribusi PDAM Tirta Bukae Luwu Utara Kec.Masamba tahun 2017 sebesar $1.280 .810 \mathrm{~m}^{3}$ dan tahun 2018 sebesar $1.456 .430 \mathrm{~m}^{3}$, Sehingga besar kehilangan air PDAM Tirta Bukae Luwu Utara Kec.Masamba pada tahun 2017 mencapai $430.684 \mathrm{~m}^{3}$ dengan kerugian mencapai Rp. 1.110.734.036 dan pada tahun 2018 mencapai 488.235 dengan total kerugian mencapai Rp. 1.259.158.065.

2. Strategi pengendalian tingkat kehilangan air yang disarankan untuk dilakukan adalah penggantian meter air yang tepat dan sesuai dengan kelompok pelanggan yang menggunakan, dilakukan kalibrasi pada meter air pelanggan secara berkala, penerapan sistem pembacaan meter air pelanggan menggunakan alat komunikasi (HP) secara menyeluruh, membentuk tim penertiban sambungan liar, memantau pelayanan air yang tidak teratur, pemasangan water meter pada jaringan transmisi dan distribusi, membuat pemetaan jaringan menggunakan GIS, membentuk tim pengendalian NRW, dan pencarian kebocoran.

\section{SARAN}

Sekiranya PDAM Tirta Bukae Luwu Utara bisa mempertimbangkan analisis yang telah saya lakukan agar dapat terpenuhinya kebutuhan air bersih pada kec. Masamba yang optimal tanpa mengalami kerugian.

\section{DAFTAR PUSTAKA}

Ardiansyah, Juwono, P. T. \& Ismoyo, M. J. (2012) Analisa Kinerja Sistem Distribusi Air Bersih Pada PDAM Di Kota Ternate. Jurnal Teknik Pengairan, 2 (3) Desember, pp. 211-220.

B. Syahputra, "Penyusunan Neraca Air sebagai Fungsi Kontrol Laju Kehilangan Air PDAM (Studi Kasus PDAM Kota Semarang),"2011

Farley. (2008). Buku Pegangan tentang Air Tak Berekening (NRW) untuk Manajer. Cipta Karya-ADBUSAID-Ranhil.

International Water Association (IWA), Losses for Water Systems : Standard Terminology and Recommended Performance Measures Water Balance. IWA Publishing, 2001.

N. A. Siregar and A. P. Mulia, "Evaluasi Kehilangan Air (WaterLosses) PDAM Tirtanadi Padangsidimpuan di Kecamatan Padangsidimpuan Selatan," J. Univ. Sumatera Utara, vol. 3, no. 1, 2013.

M. Farley, A Guide to Understanding Water Losses. 2008. Badan Standarisasi Nasional Indonesia (BSNI), "SNI 2547 : 2008 Spesifikasi Meter Air," Jakarta, 2008.

Rita, D.K. \& Nugraha, W. D. (2010). Studi Kehilangan Air Akibat Kebocoran Pipa Pada Jalur Distribusi Pdam Kota Magelang (Studi Kasus: Perumahan Armada Estate Dan Depkes, Kramat Utara Kecamatan Magelang Utara). Jurnal PRESPITASI, 7 (2): Program Studi Teknik Lingkungan FT UNDIP 